\title{
A Construção de Narrativas Digitais como Apoio ao Processo de Letramento
}

\author{
Daniela Capra de Azeredo - CINTED - UFRGS - capra.daniela@gmail.com \\ Eliseo Reategui- PGIE/PPGEDU - UFRGS - eliseoreategui@gmail.com
}

\begin{abstract}
Resumo: Este artigo apresenta uma investigação sobre como a construção de narrativas através de ambiente digital pode ser um facilitador ao processo de letramento de alunos de segundo ano do ensino fundamental. O artigo apresenta breve fundamentação teórica sobre alfabetização e letramento, discutindo aspectos relevantes sobre a inserção das tecnologias digitais neste processo. Em seguida, propõe o uso de uma ferramenta para construção de narrativas associada a práticas específicas como forma de apoio ao desenvolvimento da leitura e escrita. $O$ artigo apresenta então um experimento sobre a utilização da ferramenta Storybird com alunos do segundo ano do ensino fundamental, como apoio ao processo de letramento. Os resultados do experimento demonstraram que a ferramenta pode facilitar os processos de construção da linguagem escrita de crianças em fase de alfabetização.
\end{abstract}

Palavras-chave: Letramento, narrativas digitais, aprendizagem

\begin{abstract}
This paper presents a research about how storytelling in the digital environment may support literacy processes of second grade students. The paper presents literacy theories and discusses relevant aspects about the insertion of digital technologies in this process. Then, the paper proposes the use of a particular tool for storytelling, associated to particular pedagogical practices, as a form to support reading and writing. The paper then presents an experiment about the use of the tool Storybird with second grade students to support literacy. The results of the experiment demonstrated that the tool may support the processes of development of written language of children who are starting to read and write.
\end{abstract}

Keywords: literacy, digital storytelling, learning

\section{Introdução}

Nos dias atuais evidencia-se cada vez mais a necessidade de habilidades relacionadas à leitura e escrita que estão muito além da decifração de códigos gráficos. SOARES (2003) faz essa observação quando se refere ao final dos anos oitenta, onde se apresenta a necessidade de nomear habilidades de leitura e escrita necessárias para uma participação ativa e adequada nas práticas sociais e profissionais que envolvem a língua escrita. Vários são os estudos a respeito da aquisição das habilidades de leitura e escrita, sendo o desenvolvimento destas habilidades uma das principais tarefas da escola (MEC, 2006). Hoje, fazem parte do panorama educacional brasileiro diversos instrumentos diagnósticos, entre eles: o sistema de avaliação da educação básica (SAEB), Prova Brasil e ENEM. Dados obtidos através destes instrumentos mostram resultados pouco satisfatórios, apontando para um grande número de alunos não alfabetizados ou semialfabetizados mesmo já tendo certo tempo de escolarização. (SOARES, 1998).

Neste contexto, este projeto teve como objetivo investigar de que maneira uma

V. $11 \mathrm{~N}^{\mathrm{o}}$ 1, julho, 2013 
ferramenta digital para construção de narrativas poderia apoiar os processos de desenvolvimento de habilidades de leitura e escrita, pensando neste processo como um conjunto de habilidades indispensáveis para que o indivíduo possa ser "inserido na realidade, para compreendê-la e, também, para alterá-la, como ferramentas do entendimento" (SCHOLZE e RÖSING, 2007).

Este artigo apresenta um estudo sobre o emprego da ferramenta Storybird1 para construção de narrativas com vistas a contribuir com o desenvolvimento da leitura e escrita de crianças em fase de alfabetização.

\section{Alfabetização e Letramento}

A alfabetização é definida como o processo por meio do qual o sujeito domina símbolos gráficos e desenvolve as habilidades necessárias para utilizá-los para ler e escrever (MACIEL, et. al. 2009). Trata-se de um processo que não ocorre de forma linear, pois perpassa etapas de construção e reconstrução até que seja consolidado. Segundo Emilia Ferreiro e Ana Teberosky (1991) a criança formula hipóteses frente à escrita e através do teste, validação e reconsideração destas, a criança desenvolve sua habilidade de ler e escrever.

Alguns autores fazem uma distinção entre os termos alfabetizar e letrar. Soares (2003) afirma que alfabetizar é a ação de tornar o indivíduo capaz de ler e escrever, já letrar é ir além da alfabetização, é ensinar a ler e escrever dentro de um contexto onde a escrita e a leitura tenham sentido e façam parte da vida do aluno. Da necessidade de nomear e descrever um sujeito que faz uso da leitura e escrita respondendo as modificações ocorridas na sociedade atual surgiu a palavra letramento, termo adotado neste trabalho. O letramento implica na competência de ler e escrever para informar ou informar-se, para interagir, ampliar conhecimento, capacidade de interpretar e produzir diferentes tipos de textos, de inserir-se efetivamente no mundo da escrita, entre muitas outras. (MACIEL et. al., 2009)

A escrita para SOARES (1998, p.92) é apreendida por meio de atividades de "letramento“, ou seja, de leitura e produção de textos reais, de práticas sociais de leitura e escrita. Ainda para a autora, o letramento compreende a apropriação das técnicas para alfabetização e o habito da utilização da leitura e escrita.

Assim sendo torna-se importante desenvolver o gosto pela leitura e escrita nas séries iniciais, fazendo com que a criança possa desenvolver um conjunto de habilidades que a levem ao letramento.

\section{A Tecnologia no Processo de Aprendizagem e Letramento}

Este trabalho apresenta resultados de uma pesquisa sobre práticas pedagógicas envolvendo uma ferramenta digital como forma de apoio aos processos de letramento. Neste contexto, entende-se que o computador possa ser empregado como ferramenta educacional facilitadora da execução de determinadas tarefas, e não necessariamente como instrumento central nestas tarefas, alinhado às ideias de Valente (1998).

Aliar a informática à sala de aula, tendo o professor como mediador do processo de construção de conhecimento pode transformar um modelo de ensino que não atende mais as demandas de nossa sociedade. Sabe-se que o computador pode potencializar

\footnotetext{
${ }^{1}$ http://storybird.com/
} 
diversos processos intrínsecos aos processos educacionais, como pensar, analisar, criar, interpretar, construir conhecimento através da flexibilidade e adaptação ao ritmo de cada um.

Chaves (1985) discute a necessidade de oferecer o maior número possível de recursos e estímulos à criança. Neste sentido, entende-se que a escola tenha o importante papel de desenvolver práticas pedagógicas que façam uso destes recursos de maneira criativa e eficaz no contexto de determinados processos de aprendizagem.

Sendo assim, agregando as tecnologias no cotidiano escolar, procura-se incluir as crianças no mundo digital, dispondo uma diversidade de recursos que podem propiciar o desenvolvimento da linguagem oral e escrita, com a finalidade de apoiar o processo de letramento. Como destaca Soim et. al. (2008), a escola é o principal lugar de acesso à cultura escrita, devendo propiciar a seus alunos momentos de apropriação e utilização dessa cultura em outros momentos de sua vida, ampliando e transformado sua própria cultura.

\section{Estudo sobre emprego da Ferramenta Storybird como Apoio ao Letramento}

O experimento aqui apresentado tem como objetivo principal compreender como a construção de narrativas com o apoio de uma ferramenta digital pode ser um facilitador no processo de letramento. $O$ estudo foi desenvolvida através da modalidade estudo de caso, com cunho qualitativo e observação participante. Foi desenvolvido em uma escola da rede municipal de Porto Alegre/RS com uma turma de segundo ano do ensino fundamental. A escola é organizada por ciclos de formação. Esta forma de organização prevê que a escola se organize em três Ciclos, tendo cada um a duração de três anos, o que amplia para nove anos a escolaridade básica.

A turma selecionada possuía vinte e sete alunos, com idades que variavam dos sete anos aos dez anos. Uma forte característica da turma era que a apenas cinco alunos não se encontravam no nível 5 da escrita (escrita alfabética), conforme os estudos psicogenéticos de Ferreiro e Teberosky (1991). Outra particularidade dizia respeito a desestrutura familiar, falta de acompanhamento do desempenho escolar por parte das famílias, carência de materiais básicos para o desenvolvimento das aulas assim como infrequência, o que refletia no comportamento dos educandos. $\mathrm{O}$ importante a se destacar é que mesmo com este cenário, os alunos tinham uma percepção positiva da escola, mostrando-se entusiasmados e receptivos a desafios.

$\mathrm{Na}$ atividade desenvolvida, os alunos foram levados ao laboratório de informática com a intenção de construírem narrativas com apoio da ferramenta Storybird. A ferramenta possibilita a construção de narrativas na forma de livro digital, com a possibilidade de criar histórias através da seleção de ilustrações de diversos artistas, associando-se a estas ilustrações o texto construído. A ferramenta também possibilita o compartilhamento das histórias, a consulta e troca de comentários sobre as mesmas. A figura 1 ilustra a tela de abertura da ferramenta. 


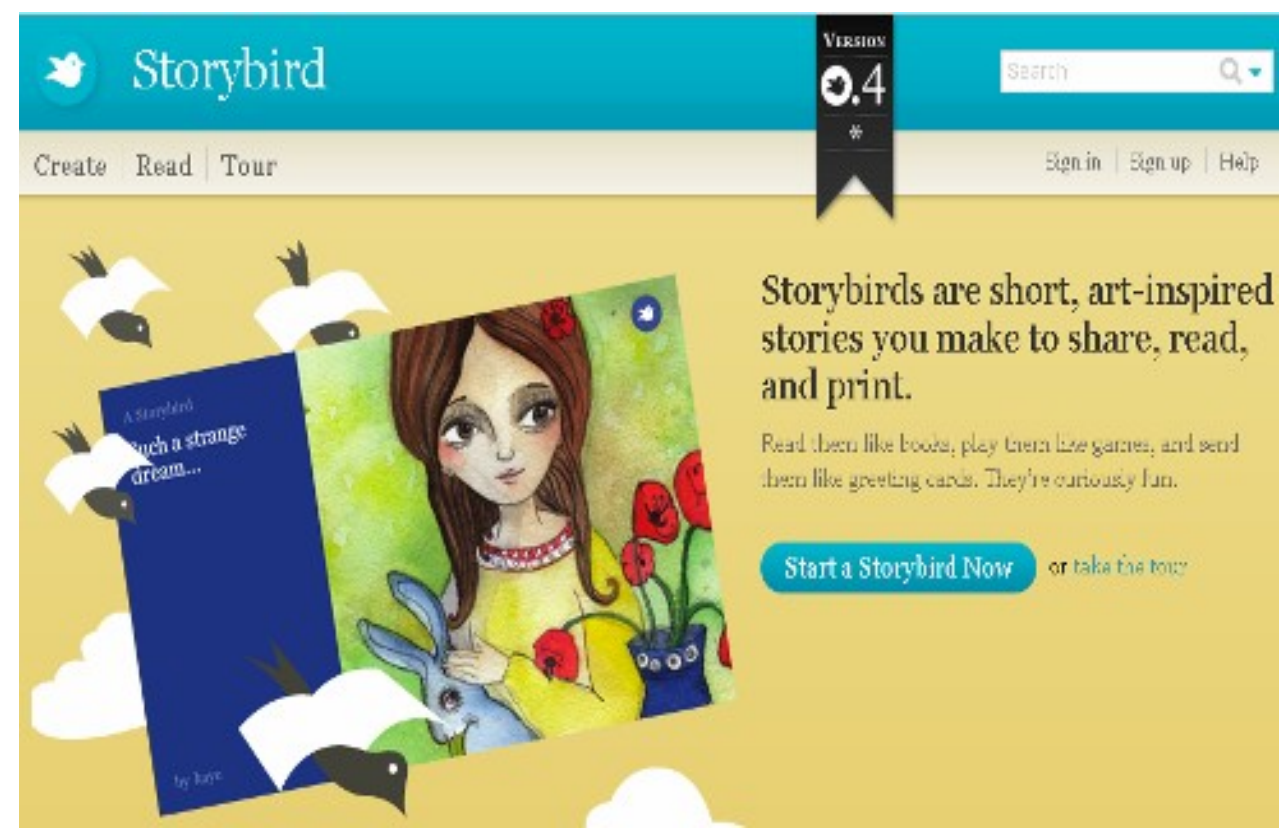

Figura 1- tela para criação de conta.

Para COELHO (2000) narrativas são resultados de uma voz que narra uma história com encadeamento de sequências vividas por personagens situados em determinado momento no tempo e espaço. Nesta pesquisa, buscou-se empregar a ferramenta Storybird em atividades de escrita nas quais o aluno fosse desafiado a construir suas narrativas de acordo com suas vivências e experiências.

Os alunos foram levados ao laboratório de informática e distribuídos em dois grandes grupos que trabalharam em momentos distintos, em função do número de computadores disponíveis no laboratório. A ideia é que cada aluno pudesse trabalhar sozinho em um computador.

Em um primeiro momento a ferramenta e suas principais funcionalidades foram apresentadas aos alunos. A partir de então a observação se direcionou sobre três alunos da turma, categorizando a pesquisa como um estudo de caso com abordagem qualitativa de coleta e análise de dados.

Passado o momento inicial de familiarização com a ferramenta Storybird, na qual os alunos aprenderam como selecionar as figuras, editar os textos e salvar as histórias, a maior parte dos alunos passou a refletir a respeito de suas escritas fazendo questionamentos sobre as convenções da língua. Após, passou-se à construção das histórias, momento no qual os alunos buscaram criar narrativas relacionadas a um conjunto de imagens selecionado. Neste momento foi possível observar a autonomia dos alunos na utilização da ferramenta, mostrando destreza na operação do Storybird, mesmo estando este em outra língua.

Durante as sessões no laboratório, buscou-se observar inicialmente dificuldades de escrita que cada um dos alunos apresentava. O quadro 1 mostra algumas destas dificuldades. 
Quadro 1 - Dificuldades apresentadas pelos alunos

\begin{tabular}{|l|l|l|l|}
\hline Dificuldades & Aluno A & Aluno B & Aluno C \\
\hline $\begin{array}{l}\text { Faz uso de sílaba } \\
\text { complexa }\end{array}$ & Sim & Algumas vezes & Sim \\
\hline $\begin{array}{l}\text { Faz uso da letra } \\
\text { maiúscula (inicio } \\
\text { de parágrafo e } \\
\text { nome próprio) }\end{array}$ & $\begin{array}{l}\text { Somente em nome } \\
\text { próprio }\end{array}$ & Não & Algumas vezes \\
\hline $\begin{array}{l}\text { Desenvolve um } \\
\text { enredo para a } \\
\text { história }\end{array}$ & $\begin{array}{l}\text { Enredo simples, } \\
\text { pouco desenvolvido }\end{array}$ & $\begin{array}{l}\text { Faz frases que } \\
\text { descrevem as } \\
\text { ilustrações } \\
\text { escolhidas }\end{array}$ & Sim \\
\hline $\begin{array}{l}\text { Demonstra } \\
\text { continuidade e } \\
\text { conexão de ideias }\end{array}$ & $\begin{array}{l}\text { De forma simples, } \\
\text { algumas vezes apenas } \\
\text { descreve as } \\
\text { ilustrações sem fazer } \\
\text { conexão com a } \\
\text { narrativa }\end{array}$ & $\begin{array}{l}\text { Faz com muita } \\
\text { dificuldade, pois } \\
\text { verbalmente } \\
\text { desenvolve a } \\
\text { narrativa, mas na } \\
\text { escrita não coloca } \\
\text { todos os elementos } \\
\text { que cita }\end{array}$ & Sim \\
\hline $\begin{array}{l}\text { Demonstra } \\
\text { criatividade }\end{array}$ & $\begin{array}{l}\text { Bim } \\
\text { Baixa }\end{array}$ & Sim \\
\hline
\end{tabular}

Dos três alunos, percebe-se que o aluno $\mathrm{C}$ apresentava maior facilidade em sua produção escrita. Os alunos A e B não incluíam em sua produção algumas das convenções comumente utilizadas na linguagem escrita, como a utilização apropriada de letra maiúscula. O enredo desenvolvido por estes alunos também mostrava-se simples, mostrando que sua produção escrita estava principalmente ligada à descrição das ilustrações escolhidas, mas não propriamente à descrição de situações relacionadas às histórias que supostamente deveriam contar.

A partir destas observações passou-se a interagir com os alunos focando nas dificuldades de cada um quanto à construção de narrativas. Após oito semanas de trabalho e de observação, percebeu-se crescimento destes frente às dificuldades apontadas anteriormente. Também foi possível observar maior engajamento dos estudantes no desenvolvimento de atividades relacionadas à produção escrita. $\mathrm{O}$ quadro 2 apresenta dados relacionados a este segundo momento de observação dos 3 estudantes que participaram do estudo.

Quadro 2 - Novas observações relacionadas às dificuldades apresentadas pelos alunos

\begin{tabular}{|l|l|l|l|}
\hline Dificuldades & Aluno 1 & Aluno 2 & Aluno 3 \\
\hline $\begin{array}{l}\text { Faz uso de sílaba } \\
\text { complexa }\end{array}$ & Sim & Algumas vezes & Sim \\
\hline $\begin{array}{l}\text { Faz uso da letra } \\
\text { maiúscula (início } \\
\text { de parágrafo e } \\
\text { nome próprio) }\end{array}$ & $\begin{array}{l}\text { Sim com maior } \\
\text { freqüência. }\end{array}$ & Algumas vezes & $\begin{array}{l}\text { Sim com maior } \\
\text { frequência. }\end{array}$ \\
\hline
\end{tabular}




\begin{tabular}{|l|l|l|l|}
\hline $\begin{array}{l}\text { Desenvolve um } \\
\text { enredo para a } \\
\text { história. }\end{array}$ & $\begin{array}{l}\text { Enredo criativo, com } \\
\text { maior complexidade. }\end{array}$ & $\begin{array}{l}\text { Enredo mais rico e } \\
\text { criativo. }\end{array}$ & $\begin{array}{l}\text { Enredo rico, com } \\
\text { maior complexidade } \\
\text { e criatividade. }\end{array}$ \\
\hline $\begin{array}{l}\text { Demonstra } \\
\text { continuidade e } \\
\text { conexão de ideias. }\end{array}$ & $\begin{array}{l}\text { Faz ligações entre as } \\
\text { páginas da história, } \\
\text { demonstrando } \\
\text { continuidade e } \\
\text { conexão de ideias. }\end{array}$ & $\begin{array}{l}\text { Passa a apresentar } \\
\text { na história um } \\
\text { número maior de } \\
\text { fatos. Demonstra } \\
\text { continuidade e } \\
\text { conexão de ideias. }\end{array}$ & $\begin{array}{l}\text { Demonstra } \\
\text { continuidade e } \\
\text { conexão de ideias } \\
\text { em uma história rica } \\
\text { e criativa. }\end{array}$ \\
\hline $\begin{array}{l}\text { Demonstra } \\
\text { criatividade. }\end{array}$ & Sim. & $\begin{array}{l}\text { Sim muita } \\
\text { criatividade e } \\
\text { imaginação. }\end{array}$ & $\begin{array}{l}\text { Sim muita } \\
\text { criatividade e } \\
\text { imaginação. }\end{array}$ \\
\hline
\end{tabular}

Observa-se neste quadro avanço de cada um dos estudantes em relação aos problemas apresentados anteriormente, como dificuldades frente à escrita das narrativas e ao uso das convenções da língua. A análise das produções escritas dos estudantes permitiu concluir que a ferramenta Storybird foi um facilitador no processo de construção das narrativas. Neste sentido, a tecnologia foi utilizada durante todo o processo de desenvolvimento e aperfeiçoamento de habilidades na sala de aula, como sugerido por Demo (1997). O envolvimento dos alunos na atividade foi algo determinante para o crescimento demonstrado. Dá-se destaque ao uso da ferramenta Storybird para este engajamento. Esta questão vai ao encontro da definição apresentada por Skinner e Belmont (1993) quando se referem ao envolvimento emocional das crianças no início de uma atividade de aprendizagem. Quando estas estão engajadas a aprendizagem acompanha um tom emocional positivo.

O desenvolvimento da atividade trouxe maior envolvimento e autonomia para os alunos participantes da pesquisa, pois passaram a acessar o site com maior independência sem a interferência do professor ou de outro adulto. Também passaram a acessar o Storbird em casa e começaram a compartilhar com seus familiares as construções das narrativas. Neste sentido, entende-se que - apesar da impossibilidade de ensinar alguém a ser autônomo - é possível criar um ambiente de liberdade, respeito e diálogo, que são condições essenciais para o sujeito fazer-se autônomo (LIMA apud MORAES, 2004).

Durante as construções das narrativas no laboratório de informática os alunos passaram a chamar os demais para ler e opinar em suas histórias. Muitas vezes esses alunos passaram a reescrever a história original após ouvir a opinião dos colegas. Tal postura mostrava envolvimento e motivação dos alunos nas atividades de escrita usando o Storybird, características apontadas por Littlewood (1997) como essenciais nos processos de aprendizagem.

A aluna A mostrou-se um sujeito ativo durante a pesquisa, retornando mais de uma vez a histórias que havia escrito para incluir as alterações sugeridas pelos colegas ou para complementar sua história e realizar correções que julgava necessárias. A aluna mostrou características definidas por Ferreiro e Teberosky (1985) como importantes para um sujeito ativo: comparou, excluiu, ordenou, categorizou, reformulou, reorganizou suas histórias.

O clima no laboratório ao final da experiência era de colaboração, participação e 
respeito pela opinião do outro. Aqui também cabe citar Vygotsky (1991) e seus apontamentos destacando que a colaboração auxilia as crianças a desenvolverem a capacidade de raciocínio, porque usam com os colegas e adultos estratégias e técnicas para solucionar problemas.

A aluna B passou a demonstrar maior auto-estima em relação ao início do estudo, onde demonstrava insegurança a respeito de sua escrita, passando a demonstrar maior confiança em suas produções. Também passou a fazer questão de chamar colegas para ler sua história e ainda comentou a atividade mais de uma vez com outras professoras. Para Branden (1994, p. 7), auto-estima tanto pode ser "[...] a confiança em nossa capacidade de pensar e enfrentar os desafios básicos da vida", como também "[...] a confiança em nosso direito de ser feliz, a sensação de que temos valor, [...] de que temos o direito de expressar nossas necessidades e desejos e de desfrutar os resultados de nossos esforços".

O aluno C surpreendeu com suas histórias. Este aluno, apesar de não demonstrar muita dificuldade na construção de suas narrativas, mostrava-se tímido no início da pesquisa. Em um segundo momento, passou a se expor mais, criando narrativas criativas e imaginativas que conquistaram os colegas, deixando-os muito envolvidos por suas histórias.

É possível concluir que a interação dos alunos com a ferramenta Storybird propiciou mudanças de comportamento positivas nos sujeitos, assim como um avanço em seus processos de produção escrita. Papert, (1980) diz que quando a criança tem a chance de explorar o objeto "computador" da sua maneira e não de uma maneira já préestabelecida pelo professor, passa a interagir com o objeto e a desenvolver outros conceitos. Assim o controle do processo de aprendizagem para as mãos do aprendiz e deixa de permanecer apenas nas mãos do professor.

\section{Considerações Finais}

A principal contribuição deste artigo foi evidenciar a possibilidade de empregar uma ferramenta de construção de narrativas apoiada pela internet para construção de histórias a fim de auxiliar o processo de letramento dos alunos de segundo ano do ensino fundamental. A ferramenta elencada para a pesquisa, o Storybird, propiciou uma atividade que engajou os estudantes que participaram do estudo e demonstrou ser facilitadora dos processos de aprendizagem relacionados ao letramento.

O uso das tecnologias é importante na atualidade, influenciando e provocando transformações na sociedade como um todo. Procurou-se ressaltar a necessidade de lançar mão da tecnologia para demandas na área da educação através do uso da informática aliada à construção de narrativas no meio digital para promoção do letramento.

As situações de construção de narrativas no ambiente digital podem auxiliar no desenvolvimento das habilidades do uso da escrita, onde o educando apropria-se do escrever como busca de interlocução e de expressão pessoal, gerando aprendizagm que deve ser proporcionada na escola (SOARES, s/d).

As histórias são fonte para diversas aprendizagens que contribuem para a construção do sujeito, pois auxiliam no desenvolvimento da imaginação, criatividade, do pensamento e da compreensão das questões afetivas. Além disso, mostram-se como excelentes recursos para conhecer a linguagem com a qual se escreve. 
MORAN (2003) entende o papel da educação numa forma mais ampla, buscando o desenvolvimento de novas competências, tais como: "(...) criatividade, criticidade, autonomia, capacidade de inovar, experienciar, transformar, refletir e resolver problemas (...)". Neste sentido, entende-se que a atividade proposta com o Storybird também contribuiu com o desenvolvimento nos alunos de habilidades de autonomia e reflexão. Na forma como as atividades foram desenvolvidas em nosso estudo, a aprendizagem foi entendida em uma concepção onde o adulto orienta e desafia a os alunos, e estes têm a liberdade de conduzir suas escolhas na criação e desenvolvimento de suas histórias (FAGUNDES apud SEABRA, 2010).

O letramento é uma das atividades mais importantes na escola, através dele também se chega à autonomia do sujeito. Neste sentido, o artigo buscou levantar dados que demonstrassem como a utilização da ferramenta Storybird poderia facilitar os processos de letramento bem como o desenvolvimento de habilidades de autonomia nos sujeitos, em atividades realizadas na escola.

\section{Referências}

BRASIL. Ministério da Educação disponível em: http://portal.mec.gov.br/ acessado em 20 de outubro de 2012.

BRANDEN, N. (1994) Como aprender a gostar de si mesmo. 38. ed., São Paulo:Saraiva.

CHAVES, Eduardo O.C. O computador na educação e informática: Projeto Educom. Rio de Janeiro, 1985.

COELHO, Nelly Novaes. Literatura infantil: teoria, análise, didática. São Paulo: Moderna, 2000.

DEMO, P Educar pela pesquisa. Campinas: Autores Associados, 1997.

FAGUNDES, Lea apud SEABRA, Carlos. Tecnologia na escola. Porto Alegre: Telos Empreendimentos Culturais, 2010.

FERREIRO, Emilia. Alfabetização em Processo. São Paulo: Cortez, 1996.144p.

LITTLEWOOD, W. Why do we want it and what can it do? In: BENSON, P.; VOLLER, P. (orgs.). Autonomy and Independence in Language Learning. New York: Addison-Wesley Longman Limited, 1997, p. 79-91.

MACIEL, Francisca Isabel Pereira et. al. A criança de seis anos e a linguagem escrita e o ensino fundamental de nove anos orientações para o trabalho com a linguagem escrita com turmas de crianças de seis anos de idade. Belo Horizonte: UFMG/FaE/CEALE, 2009.

MORAES, Roque de, LIMA, Valderes Marina do Rosário. Pesquisa em sala de aula: tendências para a educação em novos tempos. Porto Alegre: EDIPUCRS, 2004.

PAPERT, Seymour M. A Máquina das Crianças: Repensando a Escola na Era da Informática. Porto Alegre: Artes Médicas, 1993, 210 pp.

Mindstorms: Children, Computers and Powerful Ideas. Basic

Books, New York. 1980. Traduzido para o Português em 1985, como Logo: Computadores e Educação, Editora Brasiliense, São Paulo.

PIAGET, Jean. A Epistemologia Genética. Tradução: Nathanael Caixeiro. Petrópolis, Rio de Janeiro: Vozes, 1973. 
SEB/MEC. Indicadores de qualidade na educação: dimensão ensino aprendizagem da leitura e da escrita/Ação Educativa. Disponível em: http://portal.mec.gov.br/seb/arquivos/pdf/Pro_cons/indqual_2.pdf Acesso em 15 de dezembro de 2012.

SCHOLZE, Lia; RÖSING, Tânia M. K. A escrita e a leitura: fulgurações que iluminam. In: (Orgs.). Teorias e práticas de letramento. Brasília, DF: INEP/UPF, 2007.

Skinner \& Belmont (1993). Motivação em sala de aula: efeitos recíprocos de comportamento de professores e envolvimento dos alunos em todo o ano letivo. Journal of Educational Psychology, 85 (4), 571-581.

SOARES, Magda Becker. Letramento: um tema em três gêneros. Belo Horizonte: Autêntica, 1998.

SOARES, Magda Becker. Alfabetização e letramento. Contexto, 2003.

VALENTE, José Armando. Logo: conceitos, aplicações e projetos. São Paulo: Ed. McGraw-Hill. 1998.

VYGOTSKY, Lev. S. A formação social da mente. 4. ed. São Paulo: Martins Fontes, 1991. 